\title{
Results of the Recirculator Project at LLNL
}

L. Ahle, T.C. Sangster, J. Barnard, C. Burkhart, G. Craig, A. Debeling, A. Friedman, W. Fritz, D.P. Grote, E. Halaxa, R.L. Hanks, M. Hernandez, H.C. Kirbie, B.G. Logan, S.M. Lund, G. Mant, A.W. Molvik, W.M. Sharp, C. Williams

This article was submitted to $13^{\text {th }}$ International Symposium on Heavy Ion Inertial Fusion Energy, March 13-17, 2000, San Diego, CA

\section{March 2000}

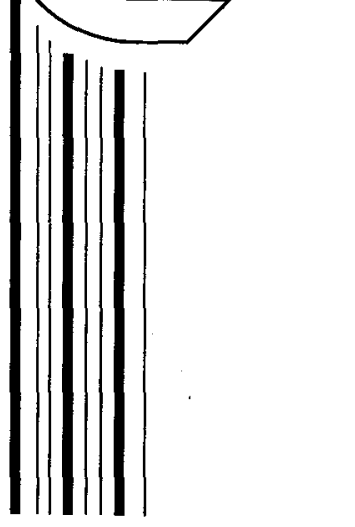




\section{DISCLAIMER}

This document was prepared as an account of work sponsored by an agency of the United States Government. Neither the United States Government nor the University of California nor any of their employees, makes any warranty, express or implied, or assumes any legal liability or responsibility for the accuracy, completeness, or usefulness of any information, apparatus, product, or process disclosed, or represents that its use would not infringe privately owned rights. Reference herein to any specific commercial product, process, or service by trade name, trademark, manufacturer, or otherwise, does not necessarily constitute or imply its endorsement, recommendation, or favoring by the United States Government or the University of California. The views and opinions of authors expressed herein do not necessarily state or reflect those of the United States Government or the University of California, and shall not be used for advertising or product endorsement purposes.

This is a preprint of a paper intended for publication in a journal or proceedings. Since changes may be made before publication, this preprint is made available with the understanding that it will not be cited or reproduced without the permission of the author.

This report has been reproduced directly from the best available copy.

Available to DOE and DOE contractors from the Office of Scientific and Technical Information

P.O. Box 62, Oak Ridge, 'TN 37831

Prices available from (423) 576-8401 http://apollo.osti.gov/bridge/

Available to the public from the National Technical Information Service

U.S. Department of Commerce 5285 Port Royal Rd., Springfield, VA 22161 http://www.ntis.gov/

\section{OR}

Lawrence Livermore National Laboratory Techuical Information Department's Digital Library http://www.llnl.gov/tid/Library.html 


\section{Results from the Recirculator Project at LLNL*}

L. Ahle ${ }^{\mathrm{a}, 1}$, T. C. Sangster ${ }^{\mathrm{a}}$, J. Barnard ${ }^{\mathrm{a}}$, Craig Burkhart ${ }^{\mathrm{c}}$, G. Craig ${ }^{\mathrm{a}}$, A. Debeling ${ }^{\mathrm{b}}$, A. Friedman ${ }^{\mathrm{a}}$, W. Fritz, D. P. Grote ${ }^{\mathrm{a}}$, E. Halaxa ${ }^{\mathrm{a}}$, R. L. Hanks ${ }^{a}$, M. Hernandez ${ }^{a}$, H. C. Kirbie ${ }^{a}$, B. G. Logan ${ }^{a}$, S. M. Lund, G. Mant ${ }^{\mathrm{a}}$, W. Molvik ${ }^{\mathrm{a}}$, W. M. Sharp ${ }^{\mathrm{a}}$, C. Williams ${ }^{\mathrm{a}}$

${ }^{a}$ Lawrence Livermore National Laboratory, Livermore, CA, 94551 USA

${ }^{b}$ Becthel Nevada Corporation, Las Vegas, NV 89030 USA

${ }^{\mathrm{c}}$ First Point Scientific, Inc., Agoura Hills, CA 91301 USA

The Heavy Ion Fusion Group at Lawrence Livermore National Laboratory has for several years been developing the world's first circular induction accelerator designed for space charge dominated ion beams. Experiments on one quarter of the ring have been completed. The accelerator extended ten half-lattice periods (HLP) with induction cores for acceleration placed on every other HLP. A network of Capacitive Beam Probes (C-probes) was also enabled for beam position monitoring throughout the bend section. These $\mathrm{C}$ probes have been instrumental in steering experiment, implementation of the acceleration stages and the dipole pulser, and the first attempts at coordinated bending and acceleration. Data from these experiments and emittance measurements will be presented.

PACS: 29.27.Bd, 29.27.Eg, 41.75.Ak, 41.85.Ja

Keywords: circular particle accelerator, space charge, induction, beam dynamics

\footnotetext{
*This work was performed under the auspices of the U.S. Department of Energy by University of California Lawrence Livermore National Laboratory under contract No. W7405-Eng-48.

${ }^{1}$ Corresponding Author, L-645, LLNL, P.O. Box 808, Livermore, CA 94551; Tel.: 925422-1621; Fax: 925-422-1767; E-mail: ahle1@llnl.gov
} 


\section{Why the Recirculator}

Currently, heavy ion beams are being pursued as a candidate for a driver of an Inertial Fusion Energy (IFE) power plant. In such a power plant, ion beams would provide the input energy necessary to ignite small D-T capsules [1]. The accelerator in such a driver would need to accelerate space charge dominated ion beams to a total kinetic energy of a few $\mathrm{GeV}$ while providing pulse compression and operate at a rate of $\sim 5 \mathrm{~Hz}$ $[2,3]$. Usually the conceptual design of such a machine is linear, but an alternative concept, which may provide significant cost savings [4], is a circular machine, or recirculator. However, a space charge dominated, ion induction, circular machine has never been built before. Thus, the HIF Group at LLNL has been developing a small recirculator in order to investigate the validity of such a concept.

\section{The Recirculator}

In order to validate the recirculator for an IFE power plant driver, coordinating bending and acceleration of the beam while maintaining transverse and longitudinal control and beam brightness must be demonstrated [5]. Table 1 lists some important characteristics of the recirculator. In designing this machine, all of the important dimensionless beam parameters, such as perveance, were kept the same as a full-scale driver machine. Each half-lattice period (HLP) of the recirculator consists of a permanent magnetic quadrupole for focusing, an electrostatic dipole for bending, induction cores for acceleration and longitudinal compression, and a capacitive beam probe, or C-probe, for position monitoring. The dipole plates are designed to bend the beam by 9 degrees while the induction cores are designed to accelerate the beam by $500 \mathrm{eV}$. The C-probes provide position measurements to within $100 \mu \mathrm{m}$. 
Figure 1 shows the layout of the machine used for the experiments presented in this paper. Initially, a $4 \mu$ seam pulse is injected by a source diode with an energy of $80 \mathrm{keV}$ through a $1 \mathrm{~cm}$ diameter aperture, providing a beam current of $2 \mathrm{~mA}$. Upon injection the beam enters an electrostatic matching section used to convert the uniformly expanding beam to an alternating focusing-defocusing beam need for transport in a quadrupole lattice. A short magnetic transport section follows which then leads to the 90 degree bend section. Following the bend section is the End Tank, which houses several diagnostics (a Faraday cup, parallel slit scanner, and a gated beam imager [6]) to measure beam quality. Also magnetic induction cores exist on 5 of the 10 HLP's as shown.

As reported earlier [7], full current transport through the $90^{\circ}$ bend section was achieved with no acceleration and DC voltages $(+/-6.575 \mathrm{kV})$ on the bending dipole plates. The RMS normalized emittance,

$$
\varepsilon_{r m s}^{2}=4 \gamma \beta\left(\left\langle x^{2}\right\rangle\left\langle x^{\prime 2}\right\rangle-\left\langle x x^{\prime}\right\rangle^{2}\right)
$$

for $90 \%$ of the full beam current after $90^{\circ}$ was found to be below the acceptable limit for emittance growth. In the bend plane, $x$, the measured value is $0.045 \pi-\mathrm{mm}-\mathrm{mR}$ while the out-of-plane, $y$, emittance is $0.068 \pi$-mm-mR. These compares to $0.021 \pi$-mm-mR measured directly after the source aperture.

\section{Match Sensitivity}

One important goal of the recirculator project is to study causes of emittance growth. One such possible cause is the matching. The requirement of a matched envelope in the bend section puts four constraints on the quadrupoles strengths in the matching section. But there are seven quads in the matching section, or seven degrees of freedom. Thus, the problem of determining the matching section quadrupole strengths is an under 
constrained problem, with many possible solutions. But do all these solutions produce the same beam quality?

In order to answer that question, four different matches, or configurations of quadrupole strengths, were determined from solving the envelope equation numerically. The four matches are called the Unique, Best, Good, and Bad match. The Unique match has the last three quads set to the same strength as the magnetic quadrupoles of the bend section. The Best and Good provide well-matched envelopes in the bend section, but the behavior of the envelopes in the matching section is more erratic for the Good match. The Bad match does not provide a well-matched envelope in the bend section and the behavior in the matching section is even more erratic than the Good match.

Table 2 lists the emittance for the four matches as measured by a slit scanner at the end of the matching section, right before the seventh quad. The measured emittance is in the $y$ plane and is measured for the two different polarity settings. Also shown is the $x$ plane emittance measured after the $90^{\circ}$ bend section. The plot shows that only the Bad match has a significantly different emittance at the end of the matching section. However, there is some difference between the matches after the bend section. At this point the Best match has the lowest emittance value, being slightly less than the Unique and Good matches. The Bad match is still the match with the highest emittance value.

Even though the Good match has similar emittance values at the end of the matching section as the other matches, the phase space plot for the Q1Y negative polarity setting showed a unique behavior. The plot is shown in figure 2 . One can clearly see a second spiral arm present in the phase space plot. As to the exact cause of this feature and why it only appears with the Good match is unclear at this time.

\section{Steering}


C-probe data from initial attempts to transport the beam through the bend section, clearly showed betatron motion in both $x$ and $y$ planes (see figure 3). The amplitude of the oscillation is significantly larger in the horizontal plane. This motion could be caused by misalignments of the source, matching section quadrupoles, straight section, or the bend section, or some combination of all four. To help ascertain the cause, steering experiments were performed using the steerers in the matching section to try and reduce the $x$ plane betatron motion to the same level observed in the $y$ plane. These steerers have the same mechanical structure as the quadrupoles, but the configuration of voltages provides dipole fields in $x$ and $y$.

In these experiments, it is assumed that most of the betatron amplitude arises from misalignments of the source and the quadrupoles before the first steerer, S1. First, the voltages on $\mathrm{S} 1$ were varied until the amplitude of the $x$ betatron motion was minimized. This condition corresponds to the beam leaving S1 parallel to the beamline center. The amplitude of the betatron motion is the offset of the beam at S1. Then, by monitoring the C-probe approximately one betatron period, 10 HLP's, away from the second steerer, S2, the field in S1 was increased until the beam centroid at S2 was near zero. Voltage were then applied to $\mathrm{S} 2$ and the strength varied until the betatron motion was minimized, which will occurs when the beam leaves S2 along the beamline center. This minimum occurs with the $S 1$ field $\sim 80 \mathrm{~V} / \mathrm{cm}$ and the $\mathrm{S} 2$ field $\sim 60 \mathrm{~V} / \mathrm{cm}$.

Figure 4 shows the measured $x$ positions through the bend section with the above steering fields applied. The betatron motion is greatly reduced by applying steering voltages, which supports the assumption that most of the betatron motion is caused by misalignments of the source and of the first few quads. The betatron motion, however, does seem to grow as the beam passes through the bend section indicating the energy of the beam and the bending dipole fields are not exactly matched. The voltages on the dipole plates are know to an accuracy of $0.2 \%$ but the energy is less well known. Therefore, the energy of the beam was lowered by $0.5 \%$, and the steering experiment was redone, with 
the steering fields becoming $\sim 130 \mathrm{~V} / \mathrm{cm}$ in $\mathrm{S} 1$ and $\sim 120 \mathrm{~V} / \mathrm{cm}$ in S2. The result is also plotted in figure 4 . The $x$ position of the $2 \mathrm{~cm}$ diameter beam now remains within $0.6 \mathrm{~mm}$ of the center all the way through the entire bend section.

\section{Bending and Acceleration}

The experiments described above were conducted with a drifting beam (no acceleration) which required only that a constant voltage be applied to the electrostatic dipoles in the HLP's. To accelerate the beam, requires a small voltage ramp (a voltage increase with time or $\mathrm{dV} / \mathrm{dt}$ ) be applied to these dipoles as the beam is accelerated. Since the electrostatic dipoles could potentially accelerate the beam, the voltages on each of the dipole plates must be of opposite. Therefore, to put a voltage ramp on the dipoles requires that one plate see a positive voltage change ( $\mathrm{dV} / \mathrm{dt}$ ) while the other sees a negative voltage change $(-\mathrm{dV} / \mathrm{dt})$. Furthermore, these ramps must be aligned precisely in time to keep the net electrostatic accelerating force at zero.

A bipolar design was developed based on a unipolar concept suggested by $\mathrm{L}$. Reginato [8]. The specifications for the pulser requires that the voltage ramp be variable (nominally $35 \mathrm{~V} / \mu \mathrm{s}$ ) under computer control, repeatable to approximately $+/-0.1 \%$, and that the net voltage offset between the two dipole plates (basically the sum of the positive and negative pulses) be less than $100 \mathrm{~V}$. The peak output voltage requirement of $+/-26 \mathrm{kV}$ was set by the total acceleration expected from multi-lap operation of the Small Recirculator. The pulser resulting from this design did meet all of the above specifications, but the +/$0.1 \%$ repeatability criterion is marginal for multi-lap operation.

The final step in coordinated bending and acceleration was the development of an induction core modulator. This pulser needs to deliver $5 \mathrm{~V}$ ms of usable acceleration gradient into the inductive load to give up to $1000 \mathrm{eV}$ of added beam kinetic energy over a 5 $\mu$ s beam pulse. The approach uses an inductive adder to deliver the required volt-seconds 
and the output pulse shape is determined by an arbitrary waveform generator under computer control (the modulator waveform is relatively complicated due to the requirement that the energized core be reset between beam pulses). Figure 5 shows the waveform delivered to the induction cores on HLP 5 and the signal from one of the pads of C-probe directly in front of the acceleration gap at HLP 5. The beam position monitor shows the beam pulse length and the figure shows the relative arrival time of the beam pulse with respect to the acceleration voltage on the induction core. One of the most important aspects of the First Point Scientific modulators is the very flat voltage during the beam transit of the induction core. This means that every beam ion is accelerated identically.

After the correct waveforms for the modulators and the dipole waveforms were determined, the relative timing of these pulses to the beam pulse must be determined. The modulators must be pulsed so there is an accelerating field when the beam passes through the acceleration gap. The dipole pulser must also be triggered at the appropriate time to insure the correct bending force on the beam. Using initial estimates, full current transport through the $90^{\circ}$ bend section was achieved with $500 \mathrm{eV}$ of beam energy added at HLP 1, 3, 5 , and 7 and ramped dipole voltage $35 \mathrm{~V} / \mu \mathrm{s}$. While full current transport was achieved, the betatron motion was optimum, so small adjustments were made to the dipole voltage ramp and its timing. Eventually, the beam was maintained to within $\sim 1 \mathrm{~mm}$ in $x$ all the way through the bend section. Figure 6 shows plots of the $x$ position of the beam with and without beam acceleration but with the dipole voltage ramped in both cases.

\section{Summary}

Experiments on the $90^{\circ}$ bend section of the LLNL Recirculator have been completed with a successful demonstration of coordinated bending and acceleration of the beam. Control of the $2 \mathrm{~cm}$ diameter beam has been demonstrated to the millimeter level and that emittance growth is below the acceptable level. Some dependence on beam quality, 
emittance, is seen with the matching solution used in the ESQ section of the lattice. With these experiments, all the necessary technology, except for insertion and extraction, have been demonstrated. 


\section{References}

[1] R. O. Bangerter, Nuovo Cimento 106A (11), 1445-1456 (1993).

[2] M. Tabak et al., Nuclear Fusion 38 (4), 509 (1998).

[3] R. Moir, "Inertial Fusion Energy Power Plants Based on Laser or Ion Beams,"

Proc. of ICENES 98, Tel-Aviv, Israel, June 28 -July 2, 1998, to be published.

[4] W. R. Meier et al., "An Integrated Systems Model for Heavy Ion Drivers," Proc. of Inter. Symp. on Heavy Ion Inertial Fusion, Heidelberg, Germany, Sept. 24-27, 1997 , to be published in Nucl. Inst. and Meth. A.

[5] A. Friedman et al., Fusion Engineering and Design 32-33, 235-246 (1996).

[6] Ahle, L. and H. S. Hopkins, "Gated Beam Imager for Heavy Ion Beams", paper presented at Beam Instrumentation Workshop, May 1998, Palo Alto, CA, AIP Conference Proceedings 451 (1998) 507-513.

[7] L. Ahle, et al., "Recent Progress in the Development of a Circular Ion Induction Accelerator for Space Charge Dominated Beams at LLNL", Proc. of LINAC98, Chicago, IL, Aug. 23-28, 1998.

[8] D. P Berners and L. L. Reginato, “Arbitrary Waveform Generator for Electrostatic 


\section{Figures}

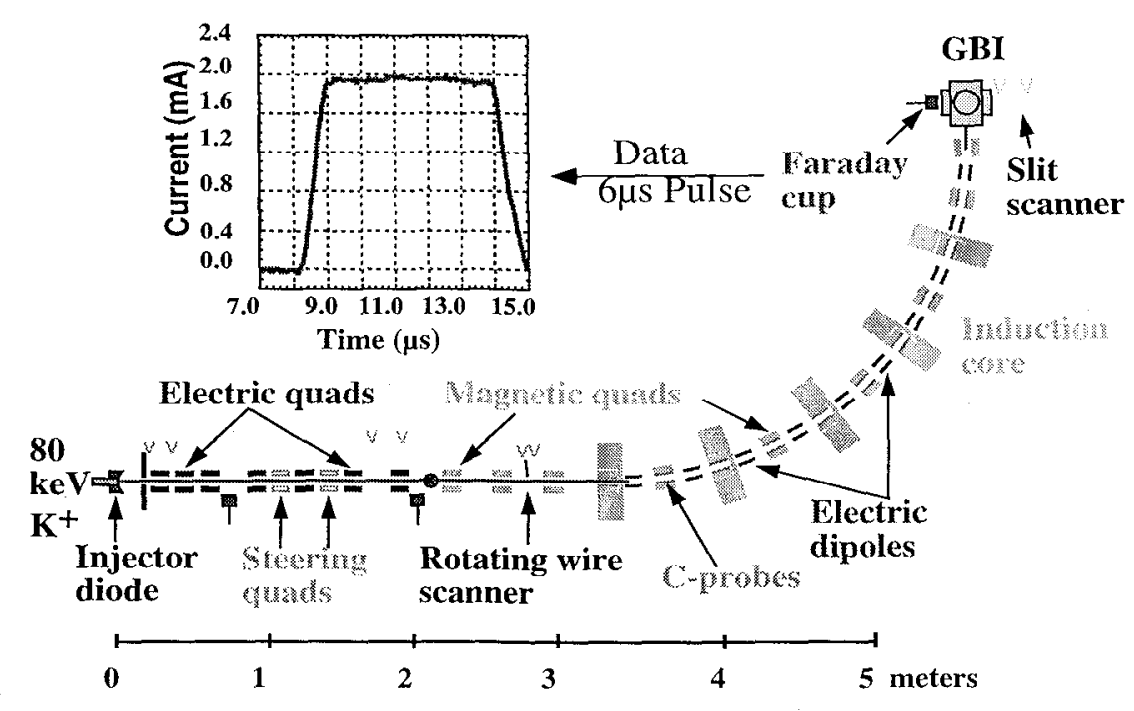

Figure 1: Layout of source, matching section and $90^{\circ}$ bend section. Also shown is signal detectedwith Faraday cup after the $90^{\circ}$ bend. 
THP.III-18

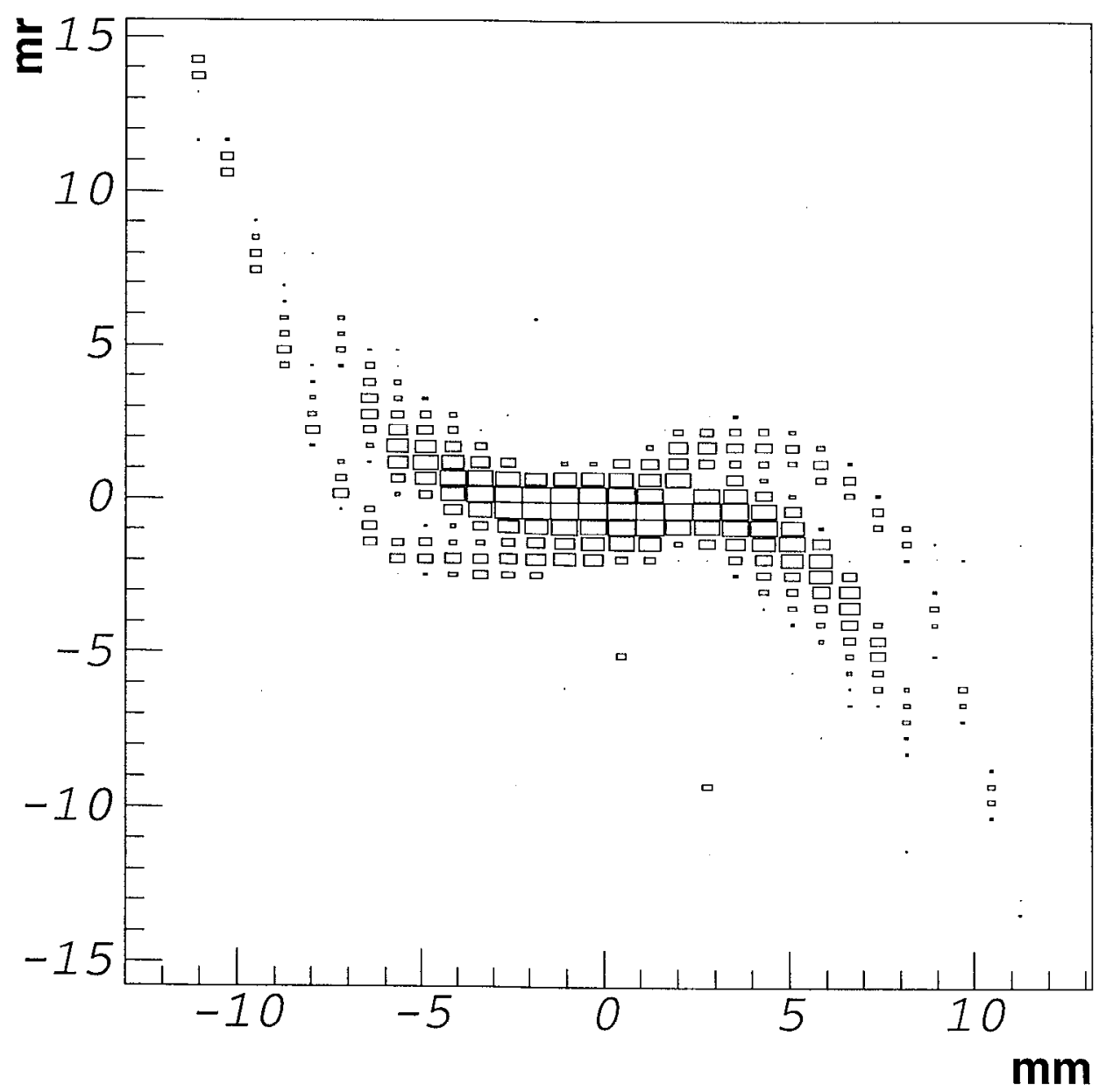

Figure 2: Phase space plot measured at end of match box with Q1Y defocussing and for the Good match. 
THP.III-18

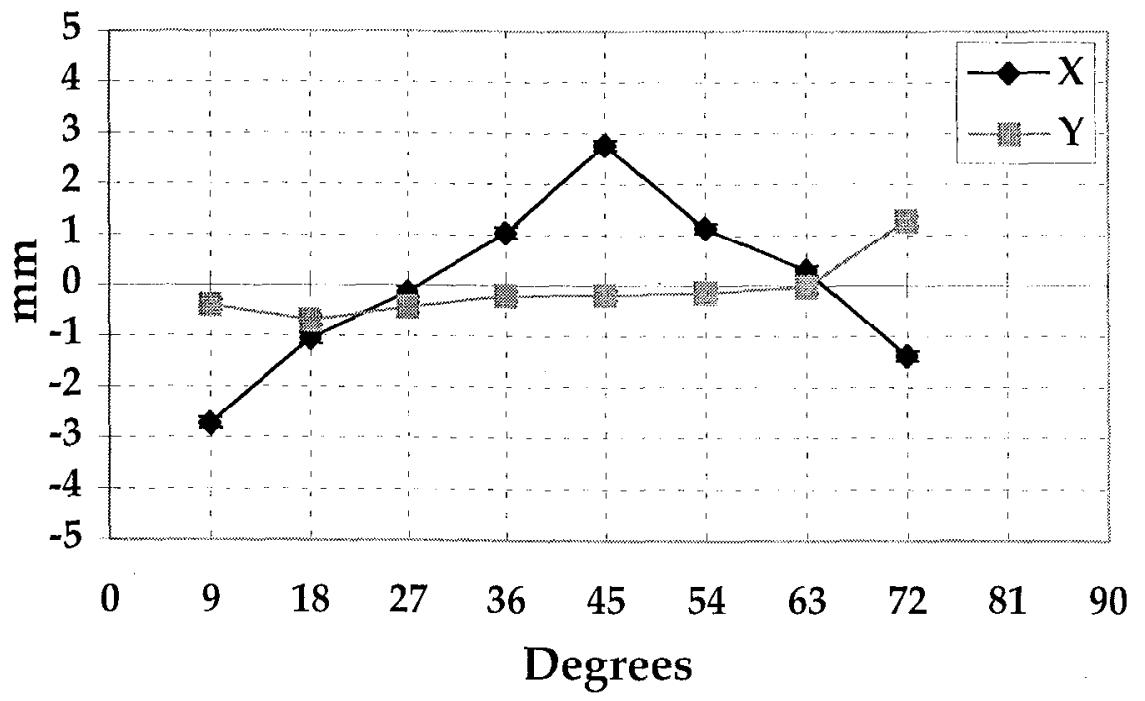

Figure 3: $\mathrm{X}$ and $\mathrm{Y}$ positions vs Bend Angle without steering. 


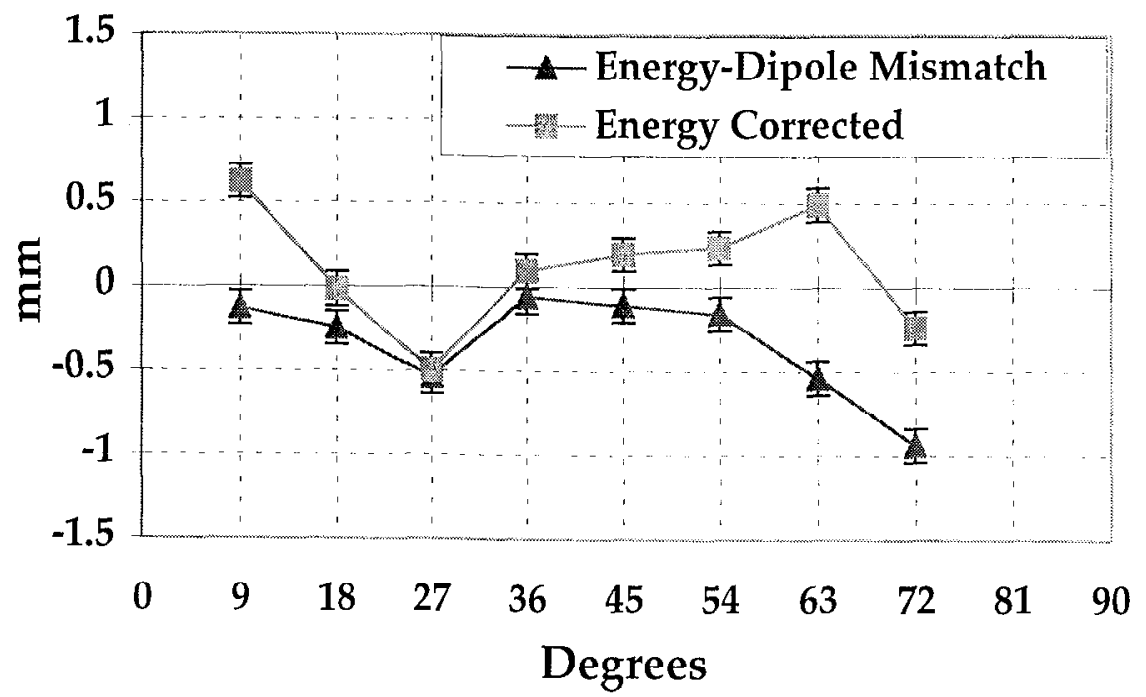

Figure 4: X positions vs Bend angle with steering before and after energy-dipole mismalch correction. 


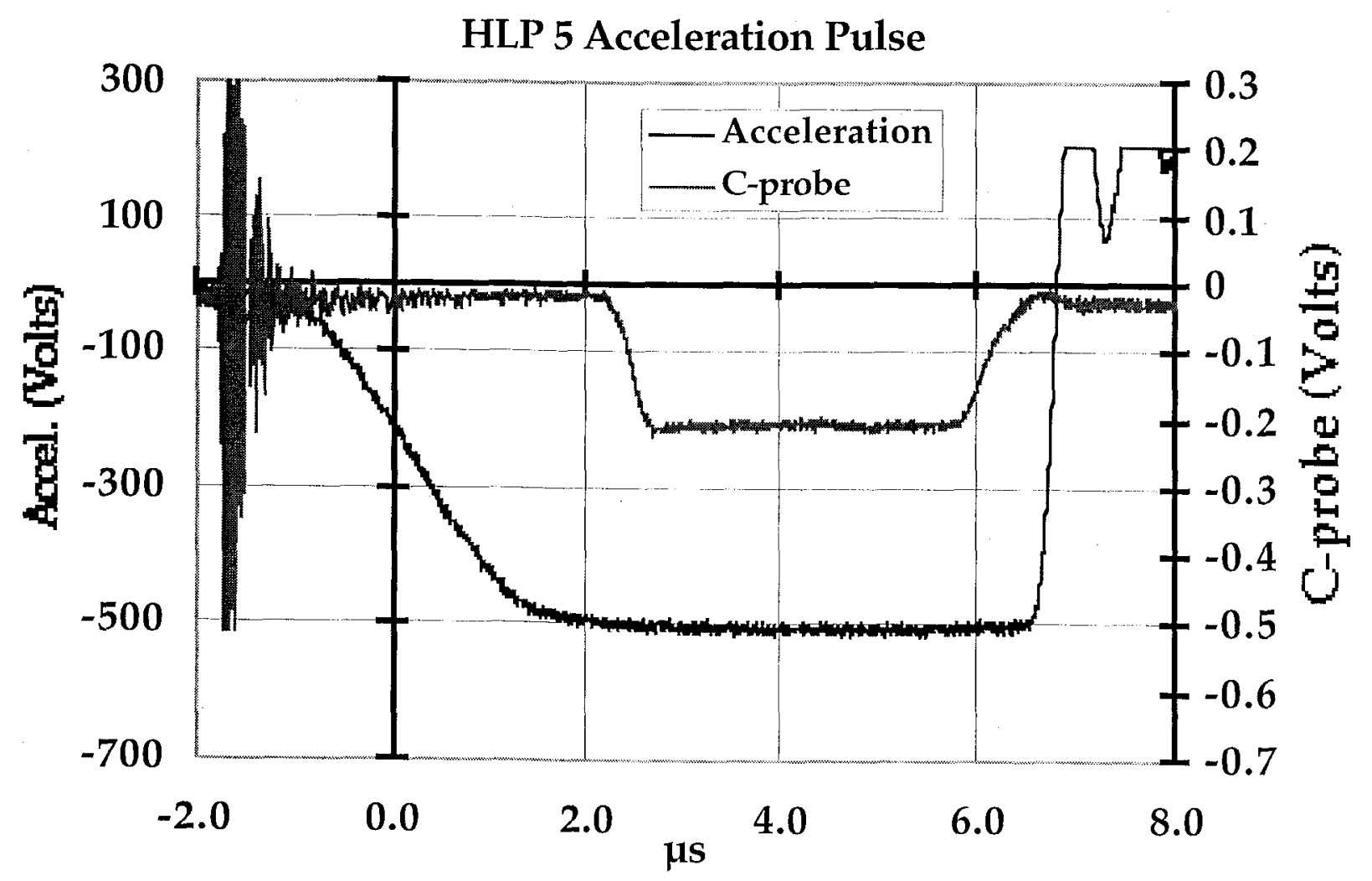

Figure 5: Plot of acceleration waveform at HLP and signal from one pad of C-probe immediately preceding acceleration gap. 


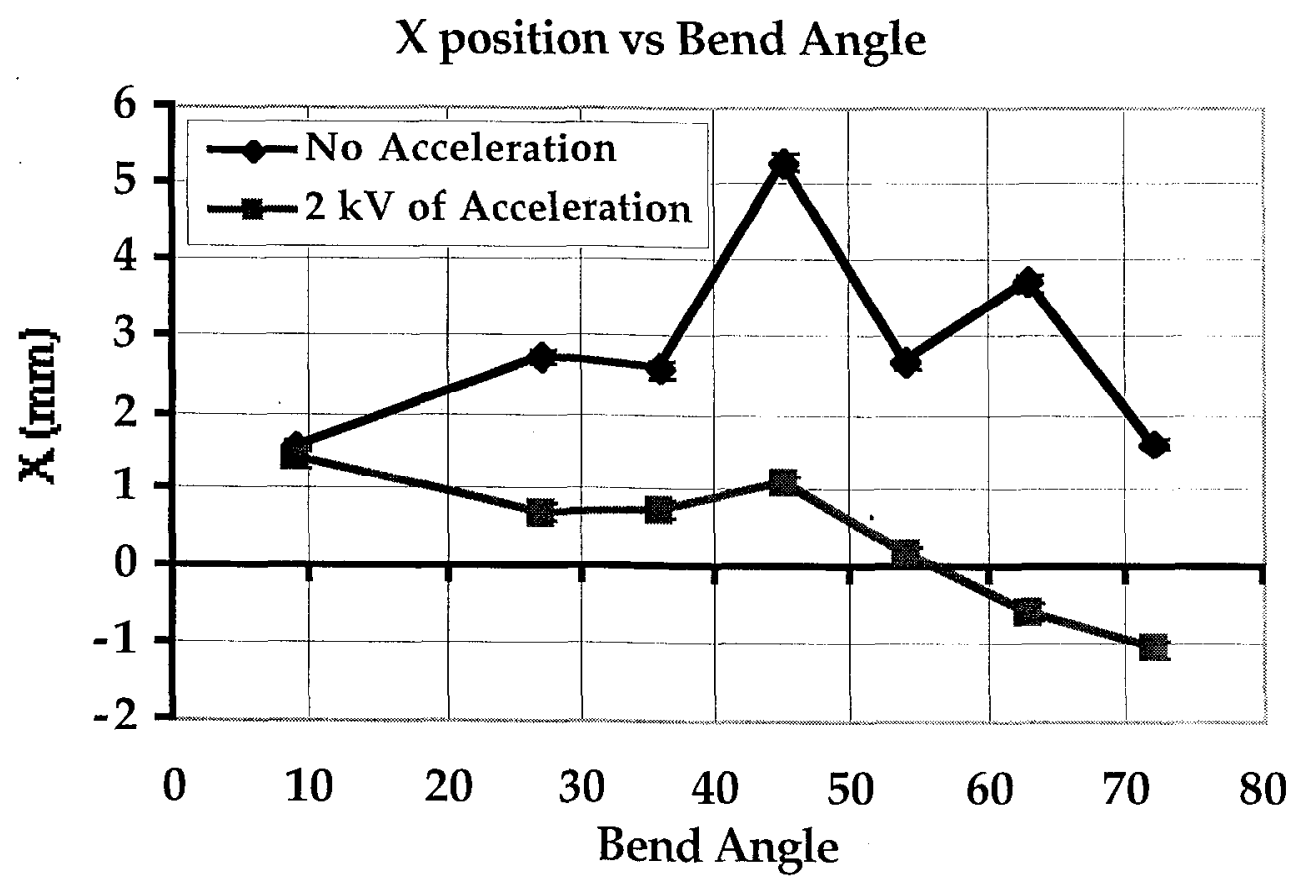

Figurc 6: Plot of $\mathrm{X}$ positions vs Bend Angle with and without $500 \mathrm{~V}$ of acceleration at $0^{\circ}$, $18^{\circ}, 36^{\circ}$, and $54^{\circ}$. In both case the dipole voltages were ramped at rate of $35 \mathrm{~V} / \mu \mathrm{s}$. 
Tables

\begin{tabular}{l|l|l}
\hline Circumference & \multicolumn{2}{|l}{$14.4 \mathrm{~m}$} \\
Beam Species & \multicolumn{2}{l}{$\mathrm{K}^{+}$} \\
\# of laps & 15 \\
Max. Beam Radius & $1.5 \mathrm{~cm}$ \\
\hline \multicolumn{1}{c|}{ Beam Statistic } & Lap 1 & \multicolumn{1}{|c}{ Lap 15 } \\
\hline Beam Energy & $80 \mathrm{keV}$ & $320 \mathrm{keV}$ \\
Pulse Duration & $4 \mu \mathrm{s}$ & $1 \mu \mathrm{s}$ \\
Beam Current & $2 \mathrm{~mA}$ & $8 \mathrm{~mA}$ \\
Undepressed Phase & $78^{\circ}$ & $45^{\circ}$ \\
Advance & $16^{\circ}$ & $12^{\circ}$ \\
Depressed Phase & & \\
Advance &
\end{tabular}

Table 1: Specifications for the Recirculator 


\begin{tabular}{c|c|c|c}
\hline & $\begin{array}{c}\text { Q1Y } \\
\text { defocus } \\
\varepsilon_{\mathrm{y}} \text { at } \\
\text { matchbox }\end{array}$ & $\begin{array}{c}\text { Q1Y } \\
\text { focus } \\
\varepsilon_{\mathrm{y}} \text { at } \\
\text { matchbox }\end{array}$ & $\begin{array}{c}\text { Q1Y } \\
\text { focus } \\
\varepsilon_{\mathrm{x}} \text { at } 90^{\circ}\end{array}$ \\
\hline Unique & 0.026 & 0.035 & 0.076 \\
Best & 0.025 & 0.039 & 0.065 \\
Good & 0.030 & 0.045 & 0.073 \\
Bad & 0.116 & 0.039 & 0.099 \\
\hline
\end{tabular}

Table 2: Measurcments of normalized emittance at various positions through lattice for difference matches. All cmittances are in $\pi$ mm-mr. 
